\title{
Oversiktsartikkel
}

\section{Abdominale aortaaneurismer - endovaskulær og åpen kirurgi}

\begin{abstract}
Sammendrag
Bakgrunn. I Norge opereres mer enn 800 abdominale aortaaneurismer årlig. Åpen operasjon for abdominalt aortaaneurisme er en etablert behandlingsform, men de siste tiårene er et økende antall pasienter blitt behandlet endovaskulært. Vi gjennomgår status for behandling av infrarenale abdominale aortaaneurismer.
\end{abstract}

\section{Materiale og metode. Det er gjort et systematisk søk på relevante artikler i Pubmed i perioden 2004-09, med søkeord «abdominal aortic aneurysm» sammen med «mortality». Vi har lagt vekt på randomiserte, multisenter- og registerstudier som sammenlikner komplikasjoner og mortalitet ved endo- vaskulær eller åpen operasjon.}

Resultater. Endovaskulær operasjon har lavere perioperativ mortalitet enn åpen operasjon. Overlevelsesgevinsten opprettholdes ikke over tid. Rumpert abdominalt aortaaneurisme har fortsatt høy mortalitet, men endovaskulær operasjon kan bedre overlevelsen hos selekterte pasienter.

Fortolkning. Selv om endovaskulær operasjon har lavere perioperativ mortalitet enn åpen operasjon for abdominalt aortaaneurisme, er flere faktorer vedrørende nytteeffekt og seleksjon av pasienter uavklart.

\author{
Morten Vetrhus \\ vemo@sus.no \\ Beate Viddal \\ Helga Loose \\ Nils Olav Neverdal \\ Erik Nordang \\ Karkirurgisk seksjon \\ Kirugisk avdeling \\ Stavanger universitetssjukehus \\ Postboks 8100 \\ 4068 Stavanger
}

Abdominale aortaaneurismer vil med økende diameter ha økende risiko for ruptur. Klinisk kan de klassifiseres som asymptomatiske, symptomatiske eller rumperte. Et symptomatisk aneurisme gir abdominalsmerter og ømhet over aneurismet uten klinisk eller radiologisk tegn til ruptur. Dette tolkes som nært forestående ruptur. Denne fremstillingen omhandler status for behandling av infrarenale abdominale aortaaneurismer, som utgjør mer enn $90 \%$ av alle abdominale aortaaneurismer.

Reseksjon av et abdominalt aortaaneurisme med interponering av et homologt transplantat (graft) ble først utført i 1951, og i Norge i 1956. Kunstige transplantat av polyesterfiber (Dacron) ble introdusert like etter. Transplantat og suturteknikk er blitt videreutviklet, men ellers er operasjonen stort sett uendret. Endovaskulær behandling ble først rapportert i 1986, og Regionsykehuset i Trondheim var forst i Norge i 1995. Operasjonen utføres via arteriene i lysken og det benyttes stenter dekket med en duk av samme materiale som ved åpne operasjoner, herav betegnelsen stentgraft. Hensikten er å ekskludere aneurismet fra sirkulasjonen for å hindre vekst og ruptur. I henhold til det karkirurgiske registeret (NORKAR) opereres det i Norge mer enn 800 abdominale aortaaneurismer årlig. Det er 18 sykehus som tilbyr åpen operasjon, av disse har ti etablert eller er i gang med å etablere endovaskulær behandling. I denne artikkelen gjennomgår vi status for behandling av infrarenale abdominale aortaaneurismer.

\section{Materiale og metode}

Vi har gjort søk på PubMed for de siste fem år. Søkeordet «abdominal aortic aneurysm» sammen med «mortality» ble benyttet, og kun artikler på engelsk eller et av de skandinaviske språkene ble vurdert. Studier der man sammenlikner komplikasjoner eller mortalitet ved åpen eller endovaskulær behandling, er blitt vektlagt i denne fremstil- lingen. Multisenter- og registerstudier er inkludert, mens studier som utgår fra ett senter kun ble inkludert dersom det var en randomisert studie. Relevante artikler er valgt og data ekstrahert av førsteforfatter (MV).

Søk på «abdominal aortic aneurysm» og «mortality» ga 1164 treff. For elektiv operasjon ble det funnet tre randomiserte (1-5), fire ikke-randomiserte multisenterstudier (6-9) og ti registerstudier (10-19).

For rumperte aneurismer finnes kun én randomisert studie (20), en preliminær rapport fra en pågående randomisert studie (21), to multisenterstudier $(22,23)$ og fire registerstudier (19, 24-26).

\section{Indikasjon og prosedyre}

Operasjon for asymptomatisk abdominalt aortaaneurisme er et profylaktisk inngrep. Hvorvidt operasjon skal tilbys eller ikke, er et spørsmål om rupturrisiko, operasjonsrisiko og forventet fremtidig levetid. Vanligvis er en diameter på $55 \mathrm{~mm}$ operasjonsindikasjon, ettersom det er et skjæringspunkt mellom rupturrisiko og operasjonsmortalitet ved denne størrelsen (27).

I overkant av $50 \%$ av infrarenale abdominale aortaaneurismer kan behandles med standard stentgraft $(2,28)$. Ligger de anatomiske forholdene til rette for endovaskulær operasjon, vil allmenntilstand, nyresvikt, tidligere laparatomier med adheranser (hostile abdomen) og alder være avgjørende for valg av type operasjon.

Ved åpen operasjon benyttes generell anestesi og det settes inn et rett eller bifurkert polyesterfibertransplantat (fig 1). Endovaskulær operasjon utføres transfemoralt og som oftest i regional anestesi (epidural). Prosedyren gjøres under gjennomlysning med kontrast, og vanligvis vil et bifurkert stentgraft med beinforlengelser benyttes. Stentgraftet holdes på plass av mothaker og den radiære kraften i metallskjelettet. Aortouniiliakale stentgraft benyttes bl.a. dersom

\section{Hovedbudskap}

- Perioperativ mortalitet er lavere etter endovaskulær enn åpen operasjon

- Langtidsoverlevelsen er lik for de to prosedyrene

- Selekterte pasienter med rumpert abdominalt aortaaneurisme kan behandles endovaskulært 
det kun er tilgang via den ene sides iliakalkar, ved aortoiliakale aneurismer og ofte ved rumperte abdominale aortaaneurismer. Kontralaterale sides iliakalkar stenges da med en plugg og en femorofemoral overkrysningsbypass anlegges for å forsørge sirkulasjon i denne underekstremiteten.

Etter endovaskulær operasjon må pasienten følges opp regelmessig i flere år med CTangiografi for å avdekke migrasjon eller lekkasje rundt stentgraftet. Kontroll etter åpen operasjon avsluttes vanligvis etter ett år.

\section{Elektive operasjoner}

Perioperative komplikasjoner

I forhold til endovaskulær operasjon medfører åpen operasjon større hemodynamiske påkjenninger, større blødning og kirurgisk traume og har høyere risiko for systemiske komplikasjoner, blant annet kardiale og respiratoriske $(3,29)$. Komplikasjonene etter endovaskulær operasjon er oftere relatert til selve implantatet og inkluderer tromboemboli, endolekkasje, implantatsokklusjon og migrasjon av stentgraftet (17).

Det er gjennomført tre randomiserte studier som sammenlikner åpen og endovaskulær elektiv operasjon. En mindre studie var designet for å undersøke livskvalitet (5), og i denne ble ikke postoperative komplikasjoner rapportert. I en av de større studiene ble det angitt behov for reintervensjon under det initiale sykehusoppholdet, og det var signifikant hyppigere etter endovaskulær enn åpen operasjon $(10 \%$ versus $6 \%, p=0,02)$ (1). I den andre så man en 30-dagers postoperativ komplikasjonsfrekvens på henholdsvis $31 \%$ etter endovaskulær og $38 \%$ etter åpen operasjon (3).

Komplikasjonstallene er ikke oppgitt i alle studiene $(8,16,19)$, men de fleste oppgir signifikant høyere komplikasjonsrater etter åpen operasjon $(6,7,10,12,14,15$, 17).

\section{Perioperativ mortalitet}

I de randomiserte studiene ble det rapportert lavere perioperativ mortalitet etter endovaskulær behandling, men forskjellen var statistisk signifikant kun i den ene (1). Perioperativ overlevelse som angitt $\mathrm{i}$ de inkluderte studiene, er oppført i tabell 1. Det store flertallet av studier anga lavere mortalitet etter endovaskulær kirurgi. Dette understøttes av en større metaanalyse (21 178 pasienter), der man finner en statistisk signifikant lavere dødelighet etter slik behandling (29).

Det har lenge vært kjent at kvinner har høyere mortalitet enn menn etter åpen operasjon, og denne kjønnsforskjellen er også er til stede etter endovaskulær operasjon $(19,30)$.

\section{Langtidsresultater}

Begge prosedyrene medfører risiko for senkomplikasjoner. Etter åpen operasjon kan det utvikles blant annet pseudoaneurismer, transplantatsinfeksjon, trombose og sekun-
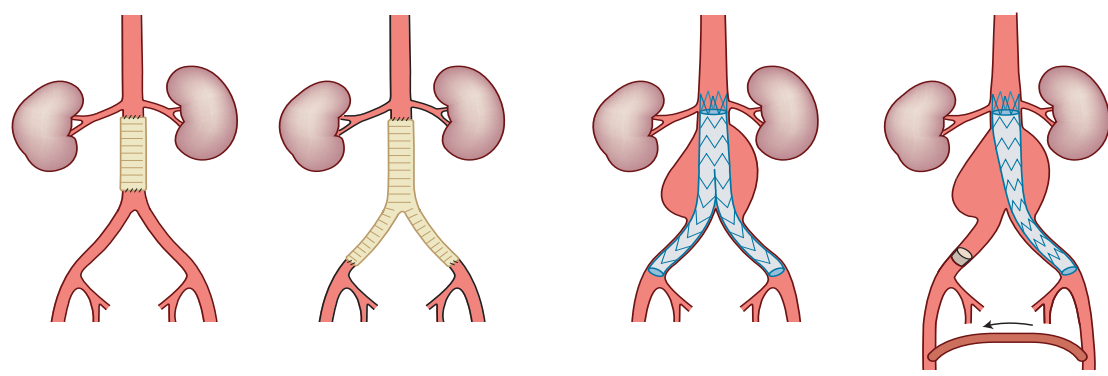

Figur 1 Rett tranplantat, bifurkert tranplantat, bifurkert stentgraft og aortouniiliacalt stentgraft

dær aortoenterisk fistel. Førstegenerasjons stentgraft hadde hyppig forekommende komplikasjoner som migrasjon med endolekkasje og derav vekst av aneurismet og fare for ruptur. En rapport fra St. Olavs hospital anga at førstegenerasjons stentgraft hadde en reintervensjonsrate på 47,5\%, redusert til 7,5\% etter introduksjon av andregenerasjons stentgraft (31).

Selv om den perioperative dødeligheten er lavere etter endovaskulær enn åpen operasjon, opprettholdes ikke denne gevinsten over to- og fireårsoppfølging $(2,4)$. Overlevelse over tid etter de to typene operasjoner er nærmest identisk, men man angir at aneurismerelatert mortalitet er høyere etter åpen operasjon. Hendelser eller komplikasjoner i løpet av oppfølgingstiden var lik for begge prosedyrer i studien med kortest oppfølgingstid, men behovet for reintervensjon var tre ganger høyere i den endovaskulære gruppen (4). I den andre studien var komplikasjonsraten høyere for endovaskulær behandling $(41 \%$ versus $9 \%, p=0,04)$ og resulterte i reintervensjon hos henholdsvis $20 \%$ og $6 \%$ av pasientene (2).

Få andre studier har langtidsoppfølging. I tre studier vistes ingen forskjell i femårsoverlevelse mellom de to operasjonsalternativene $(7,9,16)$. Etter fire års oppfølging er intervensjon relatert til aneurismet hyppigere etter endovaskulær behandling (9\% versus $1,7 \%$ ), men flere vil ha behov for kirurgi for abdominale komplikasjoner etter åpen operasjon $(9,7 \%$ versus $4,1 \%)(17)$.

\section{Pasienter med høy operasjonsrisiko}

Etter introduksjon av endovaskulær behandling av abdominale aortaaneurismer var det håp om at denne typen minimalt invasiv kir-

Tabell 1 Perioperativ mortalitet etter elektiv endovaskulær eller åpen operasjon

\begin{tabular}{|c|c|c|c|c|c|}
\hline \multirow{2}{*}{$\begin{array}{l}\text { Studie } \\
\text { Randomiserte studier }\end{array}$} & \multicolumn{2}{|c|}{ Endovaskulær operasjon } & \multicolumn{2}{|c|}{ Åpen operasjon } & \multirow[t]{2}{*}{$P$} \\
\hline & $\mathrm{N}$ & $\begin{array}{l}\text { Perioperativ } \\
\text { mortalitet (\%) }\end{array}$ & $\mathrm{N}$ & $\begin{array}{l}\text { Periope- } \\
\text { rativ mor- } \\
\text { talitet (\%) }\end{array}$ & \\
\hline EVAR 1 (1) & 529 & 1,7 & 519 & 4,7 & 0,009 \\
\hline Dream trial (3) & 171 & 1,2 & 174 & 4,6 & 0,1 \\
\hline Soulez et al (5) & 20 & 0 & 20 & 0 & - \\
\hline \multicolumn{6}{|l|}{ Andre studier } \\
\hline Aljabri et al (6) & 43 & 0 & 33 & 0 & - \\
\hline Peterson et al (7) & 334 & 1,0 & 99 & 0 & NS \\
\hline Wang et al (9) & 192 & 1 & 66 & 6,1 & $<0,039$ \\
\hline Anderson et al (10) & 871 & 0,8 & 783 & 4,2 & $<0,0001$ \\
\hline Beck et al. (11) & 639 & 0,5 & 748 & 2,3 & $<0,001$ \\
\hline Bush et al (12) & 717 & 3,1 & 1187 & 5,6 & 0,018 \\
\hline Hua et al (14) & 460 & 2,8 & 582 & 4,0 & 0,32 \\
\hline Lee et al (15) & 2565 & 1,3 & 4607 & 3,8 & 0,0001 \\
\hline Lifeline Registry (16) & 2664 & 1,7 & 334 & 1,4 & 0,72 \\
\hline Schermerhorn et al (17) & 29542 & 1,2 & 32056 & 4,8 & $<0,001$ \\
\hline \multicolumn{6}{|l|}{$\begin{array}{l}\text { Andre studier } \\
\text { (høy perioperativ risiko) }\end{array}$} \\
\hline Sicard et al (8) & 565 & 2,9 & 61 & 5,1 & 0,32 \\
\hline Bush et al (13) & 788 & 3,4 & 1580 & 5,2 & 0,047 \\
\hline Wahlgren et al (18) & 217 & 4,6 & 483 & 3,3 & 0,4 \\
\hline
\end{tabular}




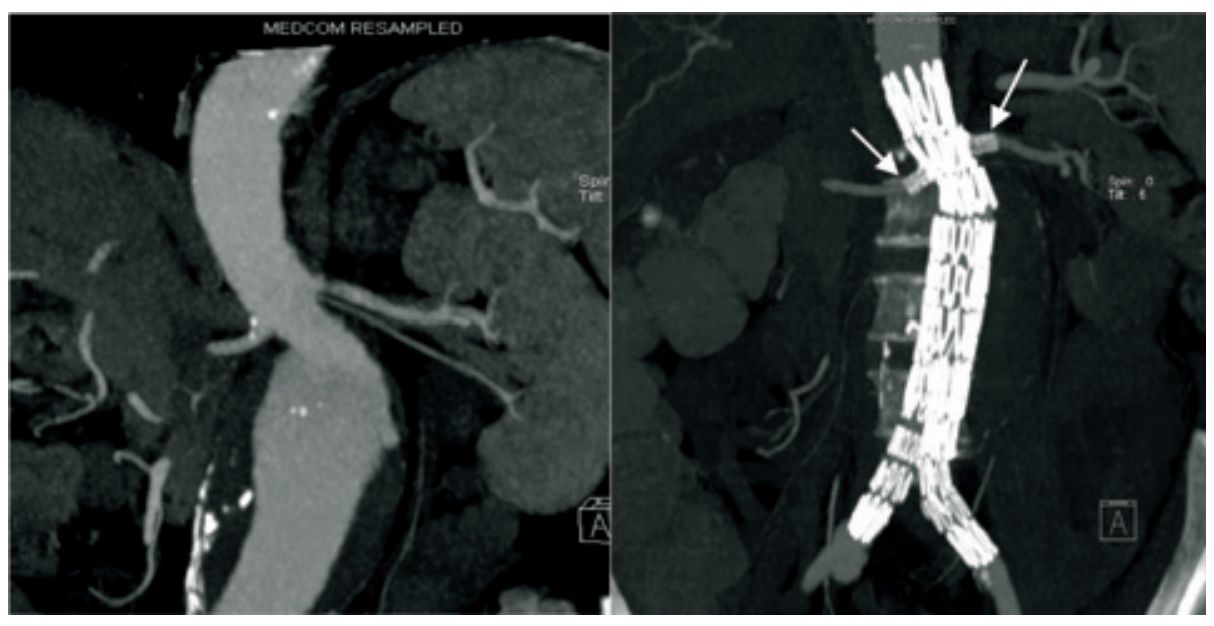

Figur 2 Aneurisme med kort hals, før og etter innsettelse av fenestrert tranplantat. Festesonen er forlenget ved å lage vinduer for nyrearteriene. Nyrearteriene er stentet (piler). Bildene er gjengitt med tillatelse av Richard McWilliams, Royal Liverpool University Hospital, Liverpool, Storbritannia

urgi ville bedre resultatene for pasienter med høy operasjonsrisiko. Det ble etter hvert rapportert om høyere postoperativ mortalitet hos denne gruppen, og i en studie randomiserte man pasienter bedømt til å ha for høy risiko for åpen kirurgi til endovaskulær behandling eller observasjon. Man fant en høy mortalitet $\mathrm{i}$ begge gruppene og ingen forskjell i overlevelse (32).

Det er ikke utført prospektive studier der man sammenlikner åpen eller endovaskulær prosedyre hos pasienter med høy operativ risiko, men det foreligger tre registerstudier. Det er ingen konsensus om definisjonen på hva som er en høyrisikopasient, men det er vanlig å inkludere alder over 60 år, ASAskår 3-4 og hjerte-, lunge- og/eller nyresykdom. Man fant i en av studiene en statistisk signifikant lavere mortalitet etter endovaskulær behandling (13), mens i en annen ble det rapportert statistisk ikke-signifikant fordel i favør av denne behandlingstypen (8) og i den siste en statistisk ikke-signifikant lavere mortalitet etter åpen operasjon (18) (tab 1).

\section{Rumperte aneurismer}

Dødeligheten for rumperte abdominale aortaaneurismer er sannsynligvis i overkant av $80 \%$ og har ikke endret seg de siste 20 årene. Kanskje så mange som $40-60 \%$ av pasientene dør før innleggelse i sykehus (33), og for de som opereres er mortaliteten fortsatt rundt $50 \%$ (34)

Rumperte aneurismer er større, og aneurismehalsen har en mer kompleks anatomi enn ved elektive abdominale aortaaneurismer (35). Det er ingen enighet om hvor stor andel av rumperte aneurismer som kan behandles endovaskulært. To studier angir at ca. $50 \%$ av pasientene har passende anatomi $(22,23)$, mens en metaanalyse angir at det tilsvarende tallet er 36-100\% (36).

Det er gjort to forsøk på randomisering mellom åpen og endovaskulær behandling av rumperte aneurismer $(20,21)$. Den ene studien inkluderer fortsatt pasienter, og det foreligger kun en preliminær rapport av hvilken andel pasienter med rumpert abdominalt aortaaneurisme som ble behandlet endovaskulært (38 av 105 pasienter, $35 \%$ ) (21). Den andre, en pilotstudie, inkluderte kun 32 av 103 vurderte pasienter (20), og det var ingen forskjell i overlevelse mellom pasienter som fikk åpen eller endovaskulær operasjon ( $53 \%$ mortalitet i begge grupper). Felles for begge studiene er det lave antall pasienter som er inkludert. En stor andel pasienter ble ikke inkludert fordi de ble bedømt som sirkulatorisk ustabile og kunne ikke få CT eller bli transportert til studiesenter (21), og mer enn halvdelen av pasientene ble bedømt som døende eller nektet operasjon (20).

Det er publisert to prospektive multisenterstudier som sammenlikner de to prosedyrene. Begge rapporterte en statistisk ikkesignifikant forskjell i 30-dagers overlevelse (endovaskulær behandling $35 \%$ og $26 \%$, åpen operasjon $39 \% \operatorname{og} 40 \%)(22,23)$.

Svenske og amerikanske registerstudier viser at andelen pasienter som behandles endovaskulært øker og utgjør i det angitte materialet $9-19 \%$ av alle operasjoner for rumpert abdominalt aortaaneurisme (19, 24-26). Den svenske studien fant en markant lavere mortalitet etter endovaskulær enn åpen operasjon (15\% versus $36 \%$, $\mathrm{p}<0,001)$ (19). Også de amerikanske studiene viste en statistisk signifikant bedre overlevelse etter endovaskulær behandling (24-26).

I to studier ble det rapportert alvorlige postoperative komplikasjoner i $60-80 \%$ av alle operasjoner uavhengig av type operasjon $(20,22)$, men med en høyere forekomst av alvorlige renale komplikasjoner etter endovaskulær behandling.

\section{Diskusjon}

Det største fortrinnet til endovaskulær operasjon for abdominale aortaaneurismer er lavere perioperativ mortalitet enn ved åpen operasjon. Det er bekymringsfullt og uvisst hvorfor denne forskjellen ikke opprettholdes over tid. Noen av studiene angir at selv om langtidsoverlevelsen er den samme uavhengig av type behandling, så er aneurismerelaterte dødsfall sjeldnere etter endovaskulær behandling (2, 4). Det er vanskelig å akseptere en slik differensiering, ettersom postmortem syning av liket har lav diagnostisk treffsikkerhet og obduksjonsfrekvensen er lav.

Mange hadde håpet at endovaskulær kirurgi ville være den beste løsningen for pasienter med høy operasjonsrisiko. Dessverre kan ikke de foreliggende studiene besvare om høyrisikopasienter eller undergrupper blant disse har best nytte av henholdsvis endovaskulær eller åpen operasjon.

Endovaskulær behandling kommer ikke til å erstatte åpen operasjon, siden mange aneurismer har en anatomi uegnet for stentgraft. Den største begrensningen vil være en for kort hals (avstanden fra nyrearteriene til starten på aneurismet). Flere setter inn standard stentgraft på korte aneurismehalser, med økt risiko for endolekkasje. For å øke andelen aneurismer som kan behandles endovaskulært er det blant annet utviklet individuelt tilpassede fenestrerte transplantat for ellers uegnede halser. Stentgraftet kan festes mer proksimalt ved å lage vinduer (fenestre) i stentgraftet for ett eller flere av de viscerale karene. Som oftest sikres plasseringen ved å sette stenter gjennom vinduene og inn i de viscerale arteriene (fig 2). Dette setter større krav til planlegging og utførelse og er atskillig mer kostbart enn standard stentgraft. Rapporterte korttidsresultater er gode, men det foreligger ingen randomiserte studier.

Rumperte abdominale aortaaneurismer forblir en stor utfordring, med liten eller ingen endring i mortalitet de siste tiårene. Endovaskulær behandling av disse krever et motivert team og medfører en lang rekke nye logistiske problem: Det er nødvendig med CT forut for kirurgi, operasjonsstuen må ha angiografiutstyr, stentgraft av forskjellige størrelser må være tilgjengelig og vaktteamet må suppleres med intervensjonsradiolog.

Da økende aneurismediameter fører til mindre fordelaktig anatomi, synes det paradoksalt at det er rapportert at majoriteten av rumperte abdominale aortaaneurismer teknisk kan behandles endovaskulært (36). Dette forklares ut ifra at man tøyer grensene og godtar anatomiske forhold som ikke er akseptable ved elektiv kirurgi. Det er å forvente at reintervensjonsraten vil være høy. De to små prospektive studiene som er gjennomført viser at andre logistiske og medisinske utfordringer er årsak til at relativt få og selekterte pasienter behandles på denne måten $(20,21)$. Bedret overlevelse etter endovaskulær behandling for abdominale aortaaneurismer med ruptur, kan skyldes seleksjonsskjevhet. 
Endovaskulær operasjon er i dag et etablert alternativ til åpen operasjon, men forutsetter livslang oppfølging. Teknologien er fortsatt under utvikling og andelen abdominale aortaaneurismer som kan behandles endovaskulært vil sannsynligvis øke. Videre studier er nødvendig for å vurdere nye eller endrede produkter. Metaanalyser vil kanskje ikke fange opp endringer i behandlingsresultat, og det er usikkert om ytterligere randomiserte studier vil gjennomføres. I Current Controlled Trials er det registrert en pågående fransk studie (elektiv operasjon) og en britisk (abdominale aortaaneurismer med ruptur) under oppstart (37).

Oppgitte interessekonflikter: Alle forfatterne har deltatt på kurs og reise arrangert av Cook Inc.

\section{Litteratur}

1. Greenhalgh RM, Brown LC, Kwong GP et al. Comparison of endovascular aneurysm repair with open repair in patients with abdominal aortic aneurysm (EVAR trial 1), 30-day operative mortality results: Randomised controlled trial. Lancet 2004; 364: 843-8.

2. EVAR trial participants. Endovascular aneurysm repair versus open repair in patients with abdominal aortic aneurysm (EVAR trial 1): Randomised controlled trial. Lancet 2005; 365: 2179-86.

3. Prinssen M, Verhoeven EL, Buth J et al. A randomized trial comparing conventional and endovascular repair of abdominal aortic aneurysms. N Engl J Med 2004; 351: 1607-18.

4. Blankensteijn JD, de Jong SE, Prinssen M et al. Two-year outcomes after conventional or endovascular repair of abdominal aortic aneurysms. N Engl J Med 2005; 352: 2398-405

5. Soulez G, Therasse E, Monfared AA et al. Pain and quality of life assessment after endovascular versus open repair of abdominal aortic aneurysms in patients at low risk. J Vasc Interv Radiol 2005; 16: $1093-100$

6. Aljabri B, Al Wahaibi K, Abner D et al. Patientreported quality of life after abdominal aortic aneurysm surgery: A prospective comparison of endovascular and open repair. J Vasc Surg 2006 44: $1182-7$

7. Peterson BG, Matsumura JS, Brewster DC et al. Five-year report of a multicenter controlled clinical trial of open versus endovascular treatment of abdominal aortic aneurysms. J Vasc Surg 2007; 45: $885-90$

8. Sicard GA, Zwolak RM, Sidawy AN et al. Endovascular abdominal aortic aneurysm repair: Longterm outcome measures in patients at high-risk for open surgery. J Vasc Surg 2006; 44: 229-36.

9. Wang GJ, Carpenter JP. The powerlink system for endovascular abdominal aortic aneurysm repair: Six-year results. J Vasc Surg 2008; 48: 535-45.
10. Anderson PL, Arons RR, Moskowitz AJ et al. A statewide experience with endovascular abdominal aortic aneurysm repair: Rapid diffusion with excellent early results. J Vasc Surg 2004; 39: $10-9$.

11. Beck AW, Goodney PP, Nolan BW et al. Predicting 1 -year mortality after elective abdominal aortic aneurysm repair. J Vasc Surg 2009; 49: 838-43: discussion 43-4.

12. Bush RL, Johnson ML, Collins TC et al. Open versus endovascular abdominal aortic aneurysm repair in VA hospitals. J Am Coll Surg 2006; 202 577-87.

13. Bush RL, Johnson ML, Hedayati N et al. Performance of endovascular aortic aneurysm repair in high-risk patients: Results from the veterans affairs national surgical quality improvement program. J Vasc Surg 2007; 45: 227-33; discussion $33-5$

14. Hua HT, Cambria RP, Chuang SK et al. Early outcomes of endovascular versus open abdominal aortic aneurysm repair in the National Surgical Quality Improvement Program-Private Sector (nsqip-ps). J Vasc Surg 2005; 41: 382 -9

15. Lee WA, Carter JW, Upchurch $G$ et al. Perioperative outcomes after open and endovascular repair of intact abdominal aortic aneurysms in the United States during 2001. J Vasc Surg 2004; 39: 491-6.

16. Lifeline Registry of EVAR Publications Committee. Lifeline registry of endovascular aneurysm repair: Long-term primary outcome measures. J Vasc Surg 2005; 42: 1-10

17. Schermerhorn ML, O'Malley AJ, Jhaveri A et al. Endovascular vs. Open repair of abdominal aortic aneurysms in the Medicare population. N Engl J Med 2008; 358: 464-74.

18. Wahlgren CM, Malmstedt J. Outcomes of endovas cular abdominal aortic aneurysm repair compared with open surgical repair in high-risk patients: Results from the Swedish Vascular Registry. J Vasc Surg 2008; 48: 1382-8.

19. Wanhainen A, Bylund N, Bjorck M. Outcome after abdominal aortic aneurysm repair in Sweden 1994-2005. Br J Surg 2008; 95: 564-70.

20. Hinchliffe RJ, Bruijstens L, MacSweeney ST et al. A randomised trial of endovascular and open surgery for ruptured abdominal aortic aneurysm results of a pilot study and lessons learned for future studies. Eur J Vasc Endovasc Surg 2006; 32: 506- 13.

21. Hoornweg LL, Wisselink W, Vahl A et al. The Amsterdam acute aneurysm trial: Suitability and application rate for endovascular repair of ruptured abdominal aortic aneurysms. Eur J Vasc Endovasc Surg 2007; 33: 679-83.

22. Peppelenbosch N, Geelkerken $\mathrm{RH}$, Soong $\mathrm{C}$ et al. Endograft treatment of ruptured abdominal aortic aneurysms using the talent aortouniiliac system: An international multicenter study. J Vasc Surg 2006; 43: 1111-23.

23. Visser JJ, Williams M, Kievit J et al. Prediction of 30-day mortality after endovascular repair or open surgery in patients with ruptured abdominal aortic aneurysms. J Vasc Surg 2009; 49: 1093-9.

24. Egorova N, Giacovelli J, Greco G et al. National outcomes for the treatment of ruptured abdominal aortic aneurysm: Comparison of open versus endovascular repairs. J Vasc Surg 2008; 48 $1092-100$.

25. Lesperance K, Andersen C, Singh N et al. Expanding use of emergency endovascular repair for ruptured abdominal aortic aneurysms: Disparities in outcomes from a nationwide perspective. J Vasc Surg 2008; 47: $1165-70$

26. McPhee J, Eslami MH, Arous EJ et al. Endovascular treatment of ruptured abdominal aortic aneurysms in the United States (2001-2006): A significant survival benefit over open repair is independently associated with increased institutional volume. J Vasc Surg 2009; 49: 817-26.

27. Mortality results for randomised controlled trial of early elective surgery or ultrasonographic surveillance for small abdominal aortic aneurysms. The UK Small Aneurysm Trial Participants. Lancet 1998; 352: 1649-55.

28. Arko FR, Filis KA, Seidel SA et al. How many patients with infrarenal aneurysms are candidates for endovascular repair? The Northern California Experience. J Endovasc Ther 2004; 11: 33-40.

29. Lovegrove RE, Javid M, Magee TR et al. A metaanalysis of 21,178 patients undergoing open or endovascular repair of abdominal aortic aneurysm. Br J Surg 2008; 95: 677-84.

30. McPhee JT, Hill JS, Eslami MH. The impact of gender on presentation, therapy, and mortality of abdominal aortic aneurysm in the United States, 2001-2004. J Vasc Surg 2007; 45: 891-9.

31. Lange C, Aasland JK, Odegard A et al. The durability of evar - what are the evidence and implications on follow-up? Scand J Surg 2008; 97: 205-12.

32. Endovascular aneurysm repair and outcome in patients unfit for open repair of abdominal aortic aneurysm (EVAR trial 2): Randomised controlled trial. Lancet 2005; 365: 2187-92.

33. Kantonen I, Lepantalo M, Brommels M et al. Mortality in ruptured abdominal aortic aneurysms. The Finnvasc Study Group. Eur J Vasc Endovasc Surg 1999; 17: 208-12

34. Hoornweg LL, Storm-Versloot MN, Ubbink DT et al. Meta analysis on mortality of ruptured abdominal aortic aneurysms. Eur J Vasc Endovasc Surg 2008; 35: 558-70.

35. Hinchliffe RJ, Alric P, Rose D et al. Comparison of morphologic features of intact and ruptured aneurysms of infrarenal abdominal aorta. J Vasc Surg 2003; 38: 88-92.

36. Harkin DW, Dillon M, Blair PH et al. Endovascular ruptured abdominal aortic aneurysm repair (EVRAR): A systematic review. Eur J Vasc Endovasc Surg 2007; 34: 673-81.

37. Current Controlled Trials. www.controlled-trials. com (10.9.2009).

Manuskriptet ble mottatt 15.1. 2009 og godkjent 10.9. 2009. Medisinsk redaktør Odd Terje Brustugun. 